\title{
Perceptions of gender roles: a case study
}

Article

Accepted Version

Kambouri-Danos, M. and Evans, A. (2019) Perceptions of gender roles: a case study. Early Years Educator (EYE), 20 (11). pp. 38-44. ISSN 1465-931X doi: https://doi.org/10.12968/eyed.2019.20.11.38 Available at https://centaur.reading.ac.uk/82763/

It is advisable to refer to the publisher's version if you intend to cite from the work. See Guidance on citing.

Identification Number/DOI: https://doi.org/10.12968/eyed.2019.20.11.38

<https://doi.org/10.12968/eyed.2019.20.11.38>

Publisher: Mark Allen Group

All outputs in CentAUR are protected by Intellectual Property Rights law, including copyright law. Copyright and IPR is retained by the creators or other copyright holders. Terms and conditions for use of this material are defined in the End User Agreement.

\section{www.reading.ac.uk/centaur}

\section{CentAUR}

Central Archive at the University of Reading

Reading's research outputs online 


\title{
Perceptions of Gender Roles within the Early Years: A Case Study Focussing on a Mainstream Reception Classroom in England
}

\author{
Maria Kambouri-Danos and Ashleigh Evans
}

Institute of Education, University of Reading, Reading, UK

\author{
m.danos@reading.ac.uk
}

\section{Introduction}

Occasionally, sex and gender refer to the same entity and consequently the two terms are used mistakenly in conversation in exchange for each other. Defining sex as explained by Oakley (1985), is the biological differences between male and female. In this way the term is bound by what is strictly anatomical. However, gender can be explained as cultural, referring to the social categorisation into men/masculine and women/feminine (Oakley, 1985). Gender can be further understood as the roles, attitudes, attributes and behaviour associated with and/or assigned to each sex (Hatchell \& Hatchell, 2007). In which case gender can be seen as subjective depending on how it has been learnt and can take various forms accordingly.

Extreme, or repeated patterns of gender behaviour or associated attributes can lead to gender stereotypes. Gender stereotypes can be explained as "standardised representations of men and women within a culture, particularly in the mass media, which polarise differences between the sexes, notably in their physical appearance, traits, behaviours, and occupations" (Chandler \& Munday, 2016, np). Thus, this paper aims to explore how these perceptions of gender and gender stereotypes are observed and understood within the early years form different perspectives. Perceptions of gender roles can also influence educational outcomes as well as impact on the child's emotional and social wellbeing yet, often educational practice still does not reflect the need to follow a gender-neutral pedagogy (Warin \& Adriany, 2017).

Previous research has focus on the perceptions of either the teachers/practitioners, the parents or the children but there is very little known about how these different views compare and contrast. This paper presents an exploratory case study into the ontology of gender within an early year's class in England, investigating the perceptions from the views of the children, practitioners and parents, comparing how they interrelate and contrast amongst themselves and with other relevant research. 
The paper aims to identify the children's perception of gender and compare the social environment surrounding the child analysing how much of the child's perceptions reflect that of the surrounding practitioners and parents. Chapman (2016) suggests that child's play is greatly influenced by the practitioners' own perceptions of gender and consequently, are confounding to the children's own view of gender roles; it will be interesting as to whether this finding is consistent within my study. The paper also provides links between gender and developmental theories, which allows to offer suggestions of why/how gender stereotypes can be found in practice and how to promote gender-neutral practices.

\section{Reviewing the literature: What we know so far}

In following with the social-constructivist theories from Bruner and Vygotsky (Doherty \& Hughes, 2009), gender can be understood as a concept which is learnt within the early years through the social interaction form of engaging with and observing adults as well as how certain behaviour from the child is received and rewarded (Massey, 2013). Other research grounded in socialisation such as MacNaughton (2000), explain how the idea of gender is a social construction and its developmental process begins at birth and then expands and develops with the child (Chapman, 2016). Whyte (1998) believes that gender role knowledge is actively developed within young children through monitoring of their social environment, in this way also echoing that of Bandura's (1977) social learning theory which emphasises the importance of learning through observation and mirrored behaviour.

Furthermore, Gender Schema Theory (GST), is based on the understanding that children learn to understand gender from the society and culture in which they live through the development of cognitive 'schemas' (Keenan, Evans, \& Crowley, 2016). Wingrave (2016) explains further how children aged 2-3 years start to identify whether they belong to a male or female category, they then begin the gendering process by categorising the world around them accordingly: those whom are the same as them and those who are not. As well as children gendering their understanding of the world, the child's perceptual development also categorises behaviour into gender; it is further suggested by that by the age of 5 children have developed firm beliefs on how girls and boys should behave (Freeman, 2007). However, interestingly, Freeman's (2007) findings suggest that children felt that their parents would approve of them playing with stereotypically gendered toys which match their sex, yet also felt that should they choose a 'cross-gender' toy the opposite sex parent would be more accepting suggesting that 
there may be some disequilibrium in the child's perception of their parent's schema's of gender and a discrepancy between theirs and that of their own.

An alternative explanation for discrepancies in children's understanding of gender relates to the age of the child. Martin and Ruble (2004) as well as Marcus and Overton (1978) suggest that children understand gender and their gender identify at a slightly later stage; gender identity, where a child can label themselves as a gender at 2 years, gender stability, where the child understands people (generally) have fixed genders throughout life at 4 years, and gender constancy at 4-5 years, where despite material decoration or appearances one still belongs to the same gender. Gender constancy being a beginning point for the gendering process has been found to be consistent internationally across many different cultures (Munroe, Shimmin \& Munroe, 1984). This poses arguments for current post-modern views of gender fluidity and transgender being apparent in young children (Knight, 2014). However, for the purposes of this paper we focus on the traditional gendering between male and female.

An encompassing theory by Tobin et al. (2010) suggests that the complexity of learning gender is acquired socially through a combination of "internalisation of gender identity, the assimilation of gender stereotypes which inform the child about gender expectations and each child's unique experience of gender, thus gender acquisition is both an individual and a societal experience." (as cited in Wingrave, 2016, p. 5). The vast amount of theory suggesting that gender is developed socially leads to the aim of the study which looks to consider the perceptions of gender in comparisons with that of the child as well as their immediate role models, parents and practitioners.

Wingrave (2016) further discusses how gender can be viewed either through socialisation or, through biological determinism. Nativist views of development consider that gender is influenced from biological determinism, that being anatomical differences between men and woman, such as differences in hormones and brain activity and the preceding differences these have on their social roles (Wingrave, 2016). Featherstone and Bayley (2010) suggest that the differences in hormone levels and how one reacts to the hormone result in variations of behaviour. For example, a strong reaction to testosterone, as primarily found in males, produces more violence and aggression whereas, a weaker reaction, as seen mostly in females results in more calm and controlled behaviour (Featherstone \& Bayley, 2010). Other theoretical bases of biological determinism are supported by the differences in brain activity between the two sexes which are argued to result in innate behavioural, cognitive and social 
differences (Schöning et al., 2007). Although, this research claims to suggest the differences seen in early childhood, the research from Schöning et al. (2007) is limited to differences found between male and female adults; yet still forms a controversial argument which counters the socialisation theory of gender as well as work of feminism. Wingrave (2016) suggests that these neurological findings may provide proof that male and females are unequivocally different. Yet, two key socialist arguments prevail: different life experiences create different neuropathways, which can result in biological differences between brains in boys and girls, especially in early childhood where the brain has higher levels of plasticity (Schmitz, 2011). Alternatively, these different neuropathways may be formed due to different experiences, treatment and opportunities due to the child's different sex itself therefore 'could be the result of gendered practices that reinforce particular behaviours and preferences' (Wingrave, 2016, p. 4). In this way, both approaches, social and biological develop of gender will be considered when analysing the data collected.

\section{What reinforces gender stereotypes}

When following the socialist theory that gender is constructed through various forms of socialisation it is important to consider what else shapes and reinforces the child's understanding of gender other than their immediate interactions with others as these factors all collaborate to form an overall understanding.

Francis (2010) promotes that gender stereotypes can be reinforced by the toys surrounding the child. By analysing a selection of favourited toys and DVD's at the time of study it was found that the girls and boys favourite toys were different in the way which they were advertised and the messages which they conceived. The girls' toys were heavily based on traditional 'gender-roles' of the female as a care-giver concerned by appearances and portrayed as a passive character; whereas the boys' toys were based on construction and perceived the male as an 'active' character who gains merit through strength and bravery (Dinella, Weisgram, $\&$ Fulcher, 2017; Francis, 2010). Toys were found to give gender suitability cues via their colour, logos and functions which indicate whether they are more communal based, for girls; or agentic based, for boys (Kollmayer, Schultes, Schober, Hodosi, \& Spiel, 2018; Wood, Desmarais, \& Gugula, 2002). The differences in how the toys were aimed to accommodate for either gender highlight explicitly to the children different messages of how each child should behave and what attitudes were associated for either gender. Additionally, the 'Letting Children 
be Children' (2011) report found that products aimed towards girls are predominantly pink, while there is a broader palate of colour for boys' clothes and toys.

Todd et al. (2018) suggests that children from a very early age show preference to playing with toys gendered towards their own gender type, this was more prominent in boys. The research found that the prominence and consistency of the findings led the practitioners to believe that the gender differences in preferences may be both social and innate. Furthermore, that male-typed toys were increasing played with as boys became older, yet this was not found with the girls, suggesting that social stereotypical effects may be more persistent in boys or, that the biological predisposition towards certain play/toy styles in boys is stronger (Todd et al., 2018), further supported by Snow, Jackline and Maccoby (1983) who suggested biologically determined preferences within boys. Although this small-scale study will not be exploring explicitly the impact of the surrounding resources in shaping the perceptions of gender in the early years, it is still factor of substantial significance which will be considered when discussing how the perceptions of gender may have been formed.

As well as gender being reinforced through toys and other resources within the child's environment, one must also consider how gender is reinforced by those whom are the immediate role models for the children predominantly, the surrounding parents and practitioners. Collins (2000) suggests how gendering is a life process and that it is learnt through the adult's behaviours and actions towards the child, further supported by Eckert and McConnell (2013), in that adults reflect their own expectations and views of what it is to be a boy or a girl (as cited in Wingrave, 2016). Similarly, a charity campaign Zero Tolerance (2013) which challenges gender stereotyping in Scotland, suggests that 'children do not exclude or devalue each other or set limits upon themselves until they learn to do so from adults. Children learn from a very young age that their behaviour, likes, dislikes and expectations should follow 'rules' about male and female roles' (Zero Tolerance, 2013, p10). Yet, research which found similar findings showed that parents believed in promoting gender equality to their children and that children in the early years should be treated the same. Furthermore, that both parents showed interest in being equally involved in their children's lives indicating less gender stereotyping in regard to the care-giving role which was once very rigid (Our Watch, 2018; Freeman, 2007). This would suggest that instead of reinforcing traditional gender stereotypes, modern parents are helping to reinforce a flexible gender understanding with less rigidity placed on the differences between either gender. 
However, Freeman's (2007) research it was found that in $100 \%$ of cases children had internalised gender stereotypes despite the fact this was not congruent with their own parent's perceptions; suggesting that there are other factors which influence gender stereotypes on children more so than what is passed on from their parents' beliefs directly. Research found discrepancies in the findings of the parents' perceptions of gender and their actual attitudes and behaviour. For example, various literature found a common occurrence that parents tended to be more liberal and accepting in regard to the girls playing with toys aimed towards either gender than to towards the boys playing with toys aimed at either gender (Freeman 2007; Kollmayer et al., 2018; Our Watch, 2018; Wood, Desmarais \& Gugula, 2002). Furthermore, Wood, Desmarais and Gugula (2002) highlight that parents often participate in gender stereotyped play with their children; however, parents are more gender flexible when they engage in play with girls. The research suggests that although parents may claim that they treat their children equally and promote gender equality, their true perceptions of the matter were indicated more explicitly through their behaviour and engagement with their children which as shown by Freeman (2007) is reinforced on impacting the children's learning of gender stereotypes. One explanation for this may be that parents question "How does one claim a genderised identity while casting away the traditional limitations that have defined gender in generations past?', (Freeman, 2007, p 363).

Another source which can impact reinforcing gender stereotypes in children are the perceptions of gender from surrounding practitioners. Research from Baig (2015) investigated how gender identity was constructed amongst girls in the early years in Pakistan. It highlights that that the perceptions of gender from that of the teachers/practitioners were of great influence on how the children regarded their own gender identity; these perceptions of gender from the practitioners were found to reflect many cultural gender stereotypes and thus, were passed onto the children's own understanding of gender. Although this study was set in Pakistan, similar findings have been found internationally by Chapman (2016) and Wingrave (2016) both of whom suggest that practitioner's perceptions of gender can influence how gender is learnt in early years through how the curriculum is implemented and their variation of expectations between genders. The interlinked comparison between both parents and practitioners and how they compare with corresponding children's' perceptions of gender is an area that have previously explored, hence the niche of this study's areas of exploration. 


\section{Impact of children's understanding of gender and gender stereotypes}

When young children are learning to understand gender from the world and adults around them, the literature has shown that it can be hard for them to avoid absorbing and internalising the gender stereotypes with dominate society. Although some loose gender stereotypes can be argued to aid the child development of gender understanding especially when considering the GST approach (Keenan et al., 2016), rigid gender stereotypes can be argued to perpetuate the social state of inequality between the sexes (Our Watch, 2018). Wingrave (2016) notes that when gender stereotypes are forced within the early years and encouraged it can contribute to a prejudice culture which can negatively impact young children by placing limitations or expectations on them which may not suit their unique, individual needs (McNaughton, 2001 as cited in Chapman 2016); a key area of learning as highlighted within the Early Years Foundation Stage Framework (DfE, 2017). Furthermore, when differences between gender evolve into discriminative limitations it can 'affect long-term confidence, opportunity, achievement, health, relationships and more' (Zero Tolerance, 2013, $\mathrm{p}$ 10). In this way, the importance of drawing attention to how these gender stereotypes are infiltrated into children's understanding is made clear as to allow children to reach their potential in an environment which is free from discrimination; a right all children have in the UK as part of the UN Convention on the Rights of the Child (UNICEF, 1989), as per the aims of this study.

Another key area which gender stereotypes impact is the one of educational opportunities. MacNaughton (2000) and Robinson and Davies (2007) note that children have fixed ideas of masculinity and femininity which affect their behaviour and choices within education, furthermore when these ideas are challenged by adults, children are reluctant to accept different ideas of gender that contrast their own perceptions of gender (as cited in Chapman, 2016). Bian, Leslie and Cimpian (2017) suggest that children as young as 6 show stereotypes discouraging girls to perceive themselves as being highly intellectual and instead favouring boys; prompting to possible explanations of gap in higher achieving jobs roles between men and woman. Yet, at the age of 5 children associate their own gender with brilliance (Bian et al., 2017), suggesting that 2-6 is the pivotal age for influence regarding gender, further supported by developmental theories of gender (Martin \& Ruble, 2004; Marcus \& Overton, 1978). Thus, from the early years adults must 'help children to deconstruct their gender binaries' (Chapman, 2016, p. 1276) should they wish to limit gender-based inequality. 
Other areas of research underline that gender stereotypes can cause negative impacts on children's emotional well-being. The charity Zero Tolerance (2013) campaign draws insights into how self-esteem, particularly in girls, was reported to be low in some children due to pressures of meeting stereotypical ideas of how different genders should look. Additionally, in extreme cases, rigid gender stereotypes is found to be a contributing, underlying factor which led to domestic abuse (Zero Tolerance, 2013; Witt, 1997).

In light of this, the study has been conducted to explore how these perceptions of gender are observed within the early years from that of the children, parents and practitioners with the aim of comparing the triangulated views and drawing comparisons of how they complement or contrast each other and whether the children within the case study are at any risk of developing limitations due to adopting gender stereotypes. Furthermore, the analysis drawn from these findings will aim to understand further what impacts these perceptions of gender and whether there is any indication of how they might have been developed or why there may be differences amongst the groups. Therefore, this paper focuses on exploring practitioners', parents' and children's perceptions of gender roles in the early years.

\section{Methodology: Planning and conducting the study}

A case study approach was adopted to support the data collection process, focusing on an early years class and the three different groups: children within the class, the parents of the children and the practitioners. The research predominantly set out to identify trends in the parent's and practitioner's responses, comparing whether this would be reflected in what was observed within the children's data and congruent with other research. The sample was taken from a mainstream early year's class in a fairly high socio-economic area. The setting is based in a small village in Berkshire (England) and has 200 children attending. All 20 children attending the reception classroom, as well as their parents and the 4 practitioners within the class were invited to take part. Four practitioners and eight parents gave their consent for themselves and their eight children to take part in the study (four boys and four girls).

The research follows the guidelines set out from the University of Reading Code of Good Practice in Research (2012) and prior to any research being conducted the study sought approval by the University Ethics Committee at the Institute of Education (University of Reading). The research also meets the ethical recommendations as set out by the British Ethical Research Association (2011). A child information sheet was produced for the children which 
is age appropriate and read to all of child participants before the research commenced (Graham, Powell, Taylor, Anderson \& Fitzgerald, 2013). In addition, parents and guardians of the children involved provided their consent; this was gained simultaneously with the obtainment of the parents' own consent to take part within the study themselves. Additionally, consent was also gained from the gatekeeper of the setting to conduct the study within their establishment as well as from all practitioners that took part. As to comply with the Data Protection Act (Great Britain, 1998) and guidelines within Roberts-Holmes (2014), all data collected was held privately by the research and to ensure privacy information was kept confidential. All names of the participants were anonymised as to protect their identity and the data will be destroyed after the study is completed. All participants who took part in the study did so under their own influence; none were paid or rewarded in any way which might have skewed the findings in either a more positive or negative light.

\section{Data Collection}

As the group of participants varied greatly in accessibility as well as social positioning, different methods were used to gather data. Overall the case study employed mixed methods of data collection. Quantitative data was collected via the use of dichotomous questions however, this was primarily used for the value of comparative grouping (Thomas, 2013); the majority of the data collected was though qualitative measures to allow for rich, personal information which could be interpreted for analysis.

Specifically, at the start of the data collection process was the parent questionnaires (Appendix 1), which were sent out allowing for a predicted two weeks turnaround time. The parents were given an option of leaving their completed questionnaires in an assigned box outside the classroom should they wish to further anonymise their feedback; otherwise the questionnaires were also collected from their children's bookbags. The next data collection method focused on looking at the various data collected from the children. This included children's literal drawings, observations and audits over a period of two weeks.

Following, two 40-minute focus group interviews were conducted with a total of four practitioners, which was recorded to allow for transcription. The interviews were conducted in a semi-structured manner and the questions were adapted from Chapman (2016) (see Appendix 2). The semi-structured style of interviews allowed for focus questions which were able to flow freely between each other as well as the ability to delve into related areas of discussion relevant 
to the topic. The interviews were non-evasively recorded to allow for a detailed transcribed of the information to later be analysed.

Considering the children's age and levels of development, the Mosaic approach was adopted to include verbal questioning and collection of drawn representations in combination with additional activities to generate information regarding the children's understanding of gender (such as puzzles and questioning from stories where gender stereotypes were challenged). This approach supported gaining a varied insight into the children's understanding of gender, as it is a multi-faceted methodology which allows children to be active members of the research whilst projecting their thoughts, feelings and ideas into tangible sources (Clark, 2005). Using a Mosaic approach allowed a collection of a varied bank of sources, enabling the creation of a more accurate, wider representation of the children's voices (Clark \& Moss, 2011). The Mosaic approach adopted here included three activities over the course of 2 weeks. These included 1) an observational audit of what the children chose to dress up as from a storybook, 2) a collection of drawn representations from the children of figures in positions of authority e.g. a police officer, a teacher/practitioner, a doctor, and 3) transcribes of verbal conversations made with the children surrounding their ideas of the question 'what a boy/girl like is?'. All information was written up for tentative comparison and further analysis.

\section{Data Analysis}

The data was analysed using the constant comparative method to de-code and find emergent themes (Thomas, 2013). The data from each group was decoded individually, and the emergent themes were analysed statically within the individual groups where possible. Numerical comparatives were made for dichotomous questions to separate into groups as a basis to show findings statically (Thomas, 2013).

This thematic analytical approach enabled the researchers to map the themes and find connections using network analysis (Thomas, 2013). In this way, the emergent themes were cross-compared to find any similarities, differences or contradicting elements which were then analysed and compared to other surrounding literature. Some areas within the data were open to interpretation, such as the drawn representations from the children. These elements of the findings were analysed first by the researcher interpreting the information based on what other areas of research suggest from similar findings and then comparing those primary findings to how they weigh in against the other emergent themes. 


\section{What did we find out: Results and Discussion}

The findings support the discussion of perceptions of gender within the early years and drew similarities from various areas of other studies in the field. When looking at the findings, it is worth keeping in mind the small sample size since our aim is not to generalise the results but rather to explore the issue. Future studies involving a larger may offer deepen our understanding, as this area of investigation is proven to be a vast, complex area to explore. To facilitate the discussion when presenting the results, the next section has been organised in three main themes, deriving from the analysis: 1) Gender as a disadvantage, 2) Gender flexibility, 3) Gender stereotypes.

\section{Gender as a Disadvantage}

One of the emerging themes, which relates to existing literature, is the perception of gender being a disadvantage, usually for girls. Findings from the parents (see figure $5 \& 6$ ) indicated that parents feel that girls face inequality because of the higher expectations from society that are placed on girls in regard to their behaviour. Parents comment that this discrimination is perpetuated into adult life where it also may negatively impact a woman's career. These ideas were further echoed by the findings from the practitioners who broadly agree with the parents and in addition offer suggestion of how toys, resources and the media also promote gender stereotypes being developed within the early years.

During the interviews, the practitioners highlighted that gender-stereotypes were reinforced by television and toys and that clear differences during children's play time were apparent. It was further felt that girls are usually the ones disadvantaged. Most importantly, all practitioners agreed that they unintentionally adhered to similar gender stereotyping in their practice. Dinella et al. (2017) as well as Francis (2010) suggest that toys as well as television shows and DVD's convey messages to children regarding gender from their advertising and functions. In this way, children are split based on their sex and limited to different toys which have different cues of how they should behave; mostly being communal based for girls and agentic based for boys (Kollmayer et al., 2018; Wood et al., 2002) setting a foundation for these gender stereotypical inequalities. Wingrave (2016) states how disadvantages arising from gender stereotypes can lead to a prejudice culture and is an area of concern from other gender equality charities as it is recognised to affect children's' opportunities, achievement and health (Zero Tolerance, 2013). 
The findings indicate that parents are concerned in relation to girl's career aspects (table 1). This is in line with research that suggests that this issue within society may be resulting from a pivotal time in children's lives when they move from associating their own gender with brilliance at the age of 5 and from as young as 6 girls show diminished ideas of self-confidence and view boys as being more intelligent (Bian et al., 2017). During the favourite book character activity, the children could choose to dress up as their favourite book character. During this activity, only girls dressed up a character of the opposite gender and twice as many girls dressed as a gender-neutral character. This confirms Bian et al. (2017) findings and the idea that children must be taught to deconstruct gender binaries to enable them to grow up with gender equal outlooks (Chapman, 2016). MacNaughton (2000) and Robinson and Davies (2007) add that once children have these fixed ideas of femininity and masculinity they are reluctant to change despite efforts from their surrounding role models.

Table 1: Key themes from parents indicated a) most felt an inequality in gender disadvantages and that b) most felt that gender is not important to their child's development.

\begin{tabular}{|l|l|}
\hline $\begin{array}{l}\text { Some parents felt that they can be more physically playful with } \\
\text { their sons as they felt the boys were stronger and more robust } \\
\mathbf{3 8 \%}\end{array}$ & $\mathbf{3 8 \%}$ \\
\hline $\begin{array}{l}\text { Some parents felt that their daughters although are not impacted } \\
\text { now, may face disadvantages as they mature in areas such as } \\
\text { work inequality } \mathbf{3 8 \%}\end{array}$ & $\mathbf{3 8 \%}$ \\
\hline $\begin{array}{l}\text { Half of the parents felt that girls also faced a disadvantage as } \\
\text { society expects more of them regarding their behaviour and } \\
\text { imposes more social restrictions on qirls than boys } \mathbf{5 0} \%\end{array}$ & $\mathbf{5 0 \%}$ \\
\hline
\end{tabular}

Biological determinist theories of gender development suggesting that anatomical differences between male and females result in gender differences may propose that the limitation of opportunities placed on girls is less one of social discrimination and more so a natural variance within gender (Schöning et al., 2007). However, following socialist arguments of brain plasticity being shaped by experience (Schmitz, 2011), biological differences in brain activity between gender are more possibly shaped by the adults around the child (Collins, 2000 \& Eckert and McConnel, 2013 as cited in Wingrave, 2016). An argument further discrediting biological theories of gender development through the findings of the cultural shift in parents' roles become more equal regarding care-giving (Our Watch, 2018; Freeman, 2007) and also 
support the study's findings that parents stated to promote equality to their children and treat them equally regardless of gender (table 2).

Table 2: Key themes from parents highlighting further details of how gender equality is felt to be promoted by parents.

\begin{tabular}{|l|l|}
\hline $\begin{array}{l}\text { Practitioners felt that they unintentionally conform to following } \\
\text { some gender stereotypes within their practice }\end{array}$ & $100 \%$ \\
\hline $\begin{array}{l}\text { Practitioners felt that TV and toys were heavily impactful towards } \\
\text { influencing gender stereotypes in the early years }\end{array}$ & $\mathbf{7 5 \%}$ \\
\hline $\begin{array}{l}\text { Practitioners felt that gender has a negative impact on girls' } \\
\text { opportunities for work as well as disadvantaging them in society } \\
\text { due to higher expectations of behaviour }\end{array}$ & $\mathbf{7 5 \%}$ \\
\hline $\begin{array}{l}\text { Practitioners felt that they observed differences between the } \\
\text { genders in behaviour; boys predominately engaging with } \\
\text { physical, agentic attributed play and girls predominately with } \\
\text { creative and communal attributed play }\end{array}$ & $\mathbf{7 5 \%}$ \\
\hline
\end{tabular}

\section{Gender Flexibility}

Findings from the children's data show that in an activity where the children took part in fancy dress, the girls appear to be more gender flexible by either being more likely to dress up as a gender-neutral character or as the opposite gender (graph 1). From these findings and when compared to other research discussing the implications of reducing gender-stereotypes and promoting gender flexibility (Our Watch, 2018; Warin \& Adriany, 2017), it can be deduced that the girls may be demonstrating a more confident and liberating gender understanding. One developmental explanation for this could be that the girls have reached the understanding of 'gender constancy' which occurs at 4-5 years (Marcus \& Overton, 1978; Martin \& Ruble, 2014) and means that the girls are of the mindset that despite material appearances they will remain the same gender thus, are able to explore characters from a wider variety. Alternatively, it is possible that due to the girls viewing their gender as a disadvantage (as discussed in the previous section), girls are more likely to adopt and embrace either a gender-neutral character or a character of the opposite gender (MacNaughton, 2000; Robinson \& Davies, 2007; Schmitz, 2011).

In addition, the explanation which is based on the 'gender consistency' developmental theory does not account for the lack of boys engaging with gender flexible play, considering they are off the same age. The findings in Figure 1 show that twice as many girls dressed up as a neutral character furthermore, that no boys chose to dress up as the opposite gender. Massey 
(2013) offers insight to this when describing that gender is learnt through the observation and internalisation of how certain behaviour is received and rewarded, in this way girls may have observed gender flexibility being more readily rewarded by adults than the boys. Interestingly, the findings are congruent with theory from other research which found in several cases parents were often more liberal and allowing of their daughters to play with either gender toys than their sons (Freeman 2007; Kollmayer et al., 2018; Our Watch, 2018; Wood, Desmarais \& Gugula, 2002).

Graph 1: Graph showing what the children dressed up as for their favourite book character. Findings show that only girls dressed up a character of the opposite gender and that twice as many girls dressed as a gender-neutral character.

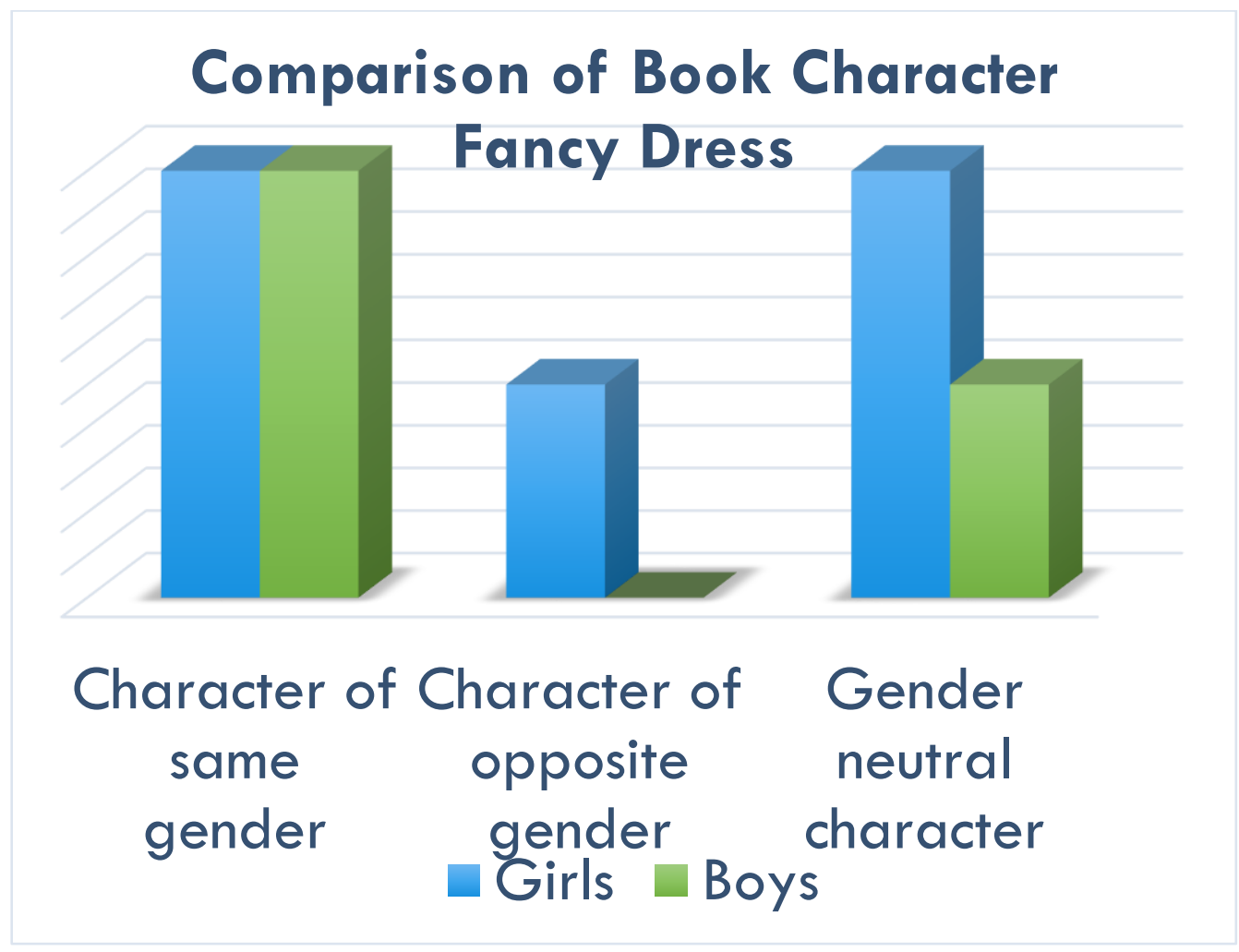

The strictness of pursuing gender stereotyped play with sons more than daughters, although found in several areas of research, was however not consistent with the findings of the study when discussed directly with the parents. When the parents were asked about how gender impacted how they interact and engage with their children, only $63 \%$ of the them indicate that they encourage their children to engage with all areas of play regardless of gender. Additionally, as found in Freeman (2007), what parents claim they do and how they act in regard to gender equality may be contradicting. Further findings show that parents feel an 
inequality in gender opportunities towards girls, this was further supported by $75 \%$ of the practitioners reporting limitations placed on girls due to gender inequality.

With this is mind, the researchers suggest a link between the two areas: girls gender flexibility and adults' behaviours towards gender. In that despite all adult participants claiming to treat children equally, the findings show more gender flexibility from the girls. This might be a result of parents and/or practitioners sympathising with the girls' perceived gender disadvantages and thus, treating them with more leniency when it comes to adopting different gender-roles during play. This suggested link is supported by Freeman's (2007) work who found discrepancies in parent's attitudes and actions towards gendered play with their children. It is also reinforced by research suggesting parents are more accepting of girls engaging with play despite gender stereotypes (Freeman 2007; Kollmayer et al., 2018; Our Watch, 2018; Wood, Desmarais \& Gugula, 2002). However, due to the study's limitations (small-scale), further research in to developing this theoretical link would be required to increase its validity.

\section{Gender Stereotypes}

Although both parents and practitioners claim to promote gender equality, there was some discrepancy found when comparing this to findings showing word associations with each gender (graph 2). The findings indicate clear patterns of themes amongst the words used for boys and girls, physical characteristics dominating to describe boys and emotional characteristics for girls; this implies differences in how the genders are wholly perceived and is consistent with gender stereotypes. These discrepancies found within the perceptions of gender from parents are also supportive of Kollmayer et. al (2018) and Freeman (2007) who also reported to find the same differences in parent's attitudes and behaviour regarding gender. Similarly, Chapman (2016) suggests that when comparing perceptions and practice from early years practitioners, either implicitly or explicitly, gender stereotypes were found to be occasionally encouraged.

Herbert and Stipek (2005) claim how 'children intuitively understand their parents' and teachers' gender-related beliefs and expectations, and this can impact on the way they view their own gender identities' (as cited in Chapman, 2016, p. 1274). In this way, it is not surprising that the children also produced findings showing some conformity to gender stereotypes when they too gave descriptive words for either gender, particularly seen when comparing the most popular words used. Yet, Freeman (2007) also notes that in 100\% of their 
data children had internalised gender stereotypes despite not being reflective of their parents' perceptions, indicating other factors of influence. One explanation of this could be the impact of toys which heavily reinforce gender stereotypes (Francis, 2010) as well as hinting to the types of behaviour stereotypically assigned to either gender (Dinella et al., 2017). The types of words found mostly associated with either gender are consistent with those found by Kollmayer et al. (2018) and Wood et al. (2002) in that boy words followed the agentic theme and girl words followed a communal theme further strengthening the findings.

Graph 2: Statistical chart to differentiate the type of words used in association with each gender. The majority of words associated with boys were based on physical characteristics whereas for girls, the words were mostly based on emotional characteristics.

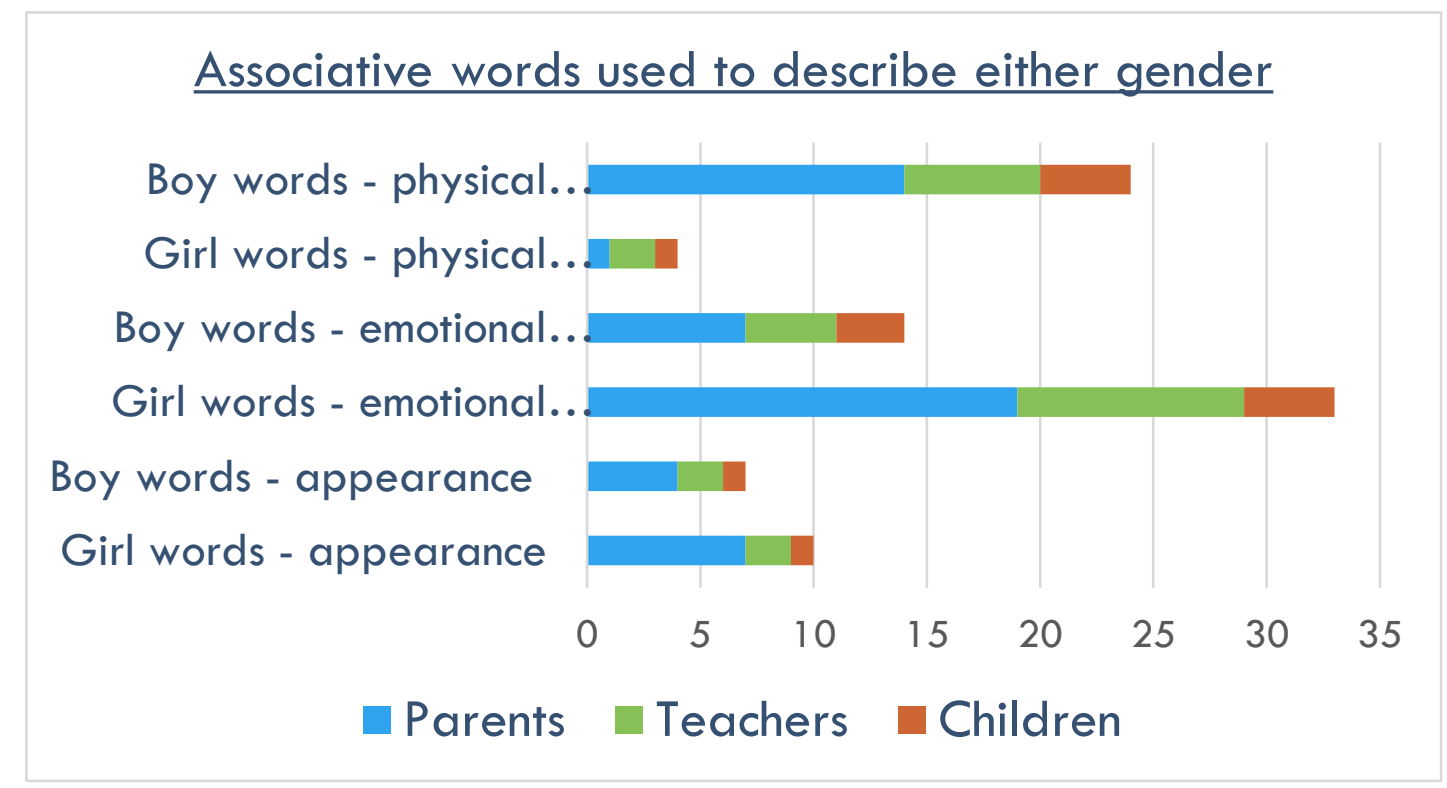

Additional findings support the above, since $100 \%$ of the practitioners admitted unintentionally following gender stereotypes despite the majority also claiming that they follow a gender-neutral practice. This links to Argyris and Schon (1974), highlighting that the practitioners may have an espoused theory of providing a gender flexible pedagogy and gender equality, yet their theory-in-use may actually be more conforming to gender stereotypes and thus, be an area of practice to address (Lindon, 2012). 
Figure 1. A selection of drawings in response to the question: 'Can you draw me a Police Officer?'. Here are 2 female police officers drawn by girls and 2 male police officers drawn by boys.

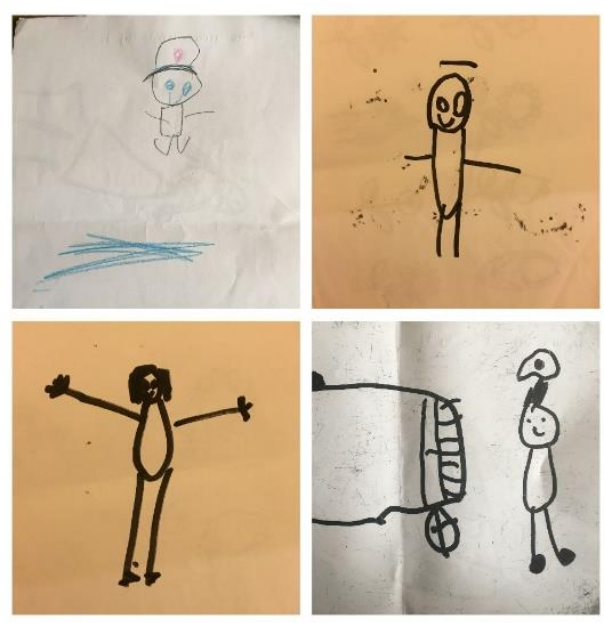

Figure 2. A selection of drawings in response to the question: 'Can you draw me a Doctor?'. From top-left to right-bottom: A male doctor and a female nurse, drawn by a boy/ A female doctor, drawn by a girl/ A female doctor, drawn by a girl/ A male doctor drawn by a boy.

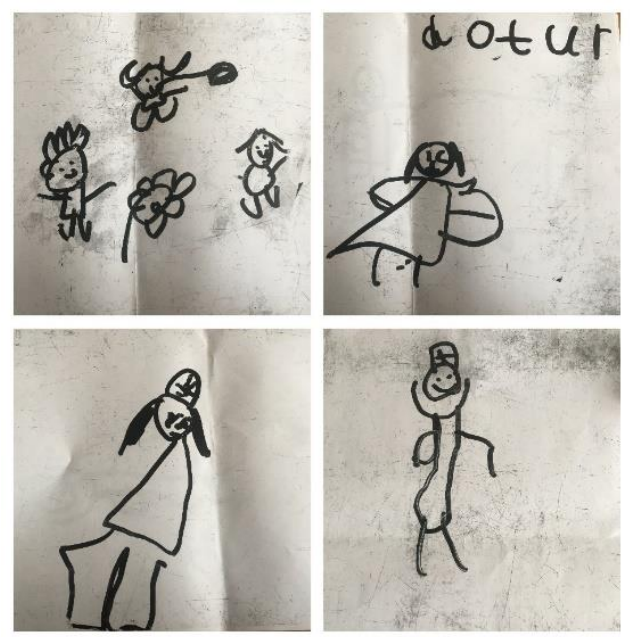

In collecting various forms of representation of the children's perceptions of gender, one activity asked the children to draw pictures of various job roles of positions of authority. When considering the findings showing representations of doctors and police officers (see figures $1 \& 2$ ) the children all identified the occupation with their own gender. The age of the children is key here when considering the results. According to Bian et al. (2017) the fact that the children's own gender is reflected in the drawings could be due to the age of the children rather than their construction of gender not limiting opportunities. In their study it was found that children aged 5 all associated their own gender with brilliance yet by the age of 6 and 7 
girls "were significantly less likely than boys to associate brilliance with their own gender" (Bian et al., 2017, p. 1). Bain et al. (2017) further suggest that this may be the source of the gender stereotype discouraging girls to be 'really really smart' and instead favouring boys leading to possibly explain the phenomenon of the gap in higher achieving jobs roles between men and woman (Bian et al., 2017; Our Watch, 2018). Wider research into gender perspectives across early years and primary education may offer further insight into this link.

\section{Conclusion}

Gender identity is developed in various forms within the early years, predominately through socialisation or biological determinism. When understanding gender and developing gender constructs there has been reported a large range of input which shows gender in a constricting view building ideas of gender stereotypes for children to absorb. Research has shown how fixed perceptions of gender which follow these stereotypical views can be damaging to children's outcomes in various areas and affect their future opportunities (MacNaughton, 2000; Robinson \& Davies, 2007). In light of this, the study aimed to explore perceptions of gender within the early years from a triangulated approach to compare against other research within the field and offer suggestions of how gender can be taught as to not perpetuate gender-based limitations. Research was conducted to obtain information regarding how gender was perceived from the parents, practitioners and children within a setting, using mixed methods of gathering qualitative data. The findings were presented and discussed in three key areas arising from the study. The first being that perceptions of gender from the adult's perspectives suggest that girls may have limited opportunities when compared to boys while the second key area proposes that girls appeare to have greater gender flexibility than boys. Linking these two areas can help to draw implications towards pedagogy in relation to how these two key areas are reflective of the parents' and practitioners' attitudes and behaviour. Interestingly, the last key area of the findings suggests that both parents and practitioners believe that gender equality is important from yet, there still appears to be a foundation of gender stereotypes acknowledged within their perceptions.

In relation to the implications in practice, it is recommended that early years settings should aim to follow practices and pedagogies that offer equality between the genders, especially during the critical transition period between 5-6 years where self confidence in girls may reduce (Bian et al., 2017). Warin and Adriany (2017) suggest that a 'gender flexible pedagogy', as seen within the Swedish curriculum, can help to reduce rigid gender stereotypes 
and allow children to understand that gender roles can be moderated, inter-relate and be flexible to their own interests. By educators being self-aware of gendered practice and actively promoting gender equality they can train children to be less accepting of traditional stereotypes whilst also offering further opportunities by encouraging learning without any gender bias (Warin \& Adriany, 2017). Educators and parents should also promote gender flexibility and should accept the different choices made by children. Finally, early years settings need to communicate regularly with parents, especially in relation to issues of equality, inclusivity and gender-neutral pedagogy, aiming to draw attention to the proposed differences in parenting between the sexes of the children (Freeman, 2007). 


\section{Reference List}

Baig, A. B. (2015). Exploring the contribution of teaching and learning processes: constructing students' gender identity in an early years classroom of a government girls primary school in Pakistan. Journal of International Women's Studies, 16(3), 1.

Bandura, A. (1977). Social learning theory. Englewood Cliffs, NJ: Prentice Hall DermanSparks.

British Ethical Research Association. (2011). Ethical Guidelines for Educational Research. London: BERA

Bian, L., Leslie, S.-J., \& Cimpian, A. (2017). Gender stereotypes about intellectual ability emerge early and influence children's interests. Science, 355(6323), 389. doi:10.1126/science.aah6524

Chandler, D., \& Munday, R. (2016). gender stereotypes. In A Dictionary of Media and Communication. Oxford: Oxford University Press. Retrieved 15 May. 2018, from http://www.oxfordreference.com.idpproxy.reading.ac.uk/view/10.1093/acref/9780 191800986.001.0001/acref-9780191800986-e-1094

Chapman, R. (2016). A case study of gendered play in preschools: how early childhood educators' perceptions of gender influence children's play. Early Child Development and Care, 186(8), 1271-1284. doi:10.1080/03004430.2015.1089435

Clark, A. (2005) 'Ways of seeing: using the Mosaic approach to listen to young children's perspectives', in Clark, A., Kjørholt and Moss, P. (eds.) Beyond Listening. Children's perspectives on early childhood services. Bristol: Policy Press, pp. 29-49.

Clark, A., \& Moss, P. (2011). Listening to young children: The mosaic approach ( $2^{\text {nd }}$ ed.). London: National Children's Bureau.

Dinella, L. M., Weisgram, E. S., \& Fulcher, M. (2017). Children's Gender-Typed Toy Interests: Does Propulsion Matter? Archives of Sexual Behavior, 46(5), 1295. doi:10.1007/s10508-016-0901-5

Doherty, J., \& Hughes, M. (2009). Child development : theory and practice 0-11. Harlow: Pearson Longman. 
Featherstone, S. \& Bayley, R. (2010). The cleverness of boys: understanding what boys do well and helping them to succeed. London: A\&C Black Publishers ltd.

Francis, B. (2010). Gender, toys and learning. Oxford Review of Education, 36(3), 325-344. doi:10.1080/03054981003732278

Freeman, N. K. (2007). Preschoolers' Perceptions of Gender Appropriate Toys and their Parents' Beliefs About Genderized Behaviors: Miscommunication, Mixed Messages, or Hidden Truths? Early Childhood Education Journal, 34(5), 357-366. doi:10.1007/s10643-006-0123-x

Graham, A., Powell, M., Taylor, N., Anderson, D. \& Fitzgerald, R. (2013). Ethical Research Involving Children. Florence: UNICEF Office of Research - Innocenti.

Great Britain. (1998). Data Protection Act. London: Stationery Office

Hatchell, H., \& Hatchell, H. (2007). Gender. In M. Flood, J. K. Gardiner, B. Pease, \& et. al. (Eds.), International encyclopedia of men and masculinities. London, UK: Routledge. Retrieved from https://search-credoreferencecom.idpproxy.reading.ac.uk/content/topic/gender?institutionId=158

Keenan, T. R., Evans, S., \& Crowley, K. (2016). An introduction to child development (3rd ed.). London: SAGE.

Knight, R. (2014). Free to be you and me: Normal gender-role fluidity - Commentary on Diane Ehrensaft's "Listening and learning from gender-nonconforming children". Psychoanalytic Study of the Child, 68, 57-70.

Kollmayer, M., Schultes, M.-T., Schober, B., Hodosi, T., \& Spiel, C. (2018). Parents' Judgments about the Desirability of Toys for Their Children: Associations with Gender Role Attitudes, Gender-typing of Toys, and Demographics. Sex Roles, 1-13. doi:10.1007/s11199-017-0882-4

Lindon, J. (2012). Reflective Practice and Early Years Professionalism. (2 ${ }^{\text {nd }}$ ed.). London: Hodder Education

MacNaughton, G. (2000). Rethinking Gender in Early Childhood Education. Sage

Marcus, D. \& Overton, W. (1978) The Development of Cognitive Gender Constancy and Sex Role Preferences: Child Development, 49(2), 434-444. 
Martin, C. \& Ruble, D. (2004.) Children's search for gender cues: cognitive perspectives on gender development. Current directions of psychological science 13(2), 67-70.

Massey, D. (2013). Space, Place and Gender. In (pp. 1 online resource (477 p.)). Retrieved from http://reading.eblib.com/patron/FullRecord.aspx?p=1584059

Munroe, R. H., Shimmin, H. S., \& Munroe, R. L. (1984). Gender understanding and sex role preference in four cultures. Developmental Psychology, 20, 673-682.

Oakley, A. (1985). Sex, gender and society (Rev. ed.). Aldershot: Arena.

Our Watch (2018). Challenging gender stereotypes in the early years: the power of parents. Melbourne, Australia: Our Watch. Witt, S. (1997) Parental influence on children's socialization to gender roles, Adolescence, (32), 125 -253, from http://gozips.uakron. edu/ susan8/parinf.htm

Roberts-Holmes, R. (2014). Doing your early years research project: a step-by-step guide. $\left(3^{\text {rd }}\right.$ ed.). London: Sage

Schmitz, S. (2011). Sex, gender, and the brain - Biological determinism versus socio-cultural constructivism. Sex and gender in biomedicine: Theories, methodologies, results, 5776.

Schöning, S., Engelien, A., Kugel, H., Schäfer, S., Schiffbauer, H., Zwitserlood, P., . . Konrad, C. (2007). Functional anatomy of visuo-spatial working memory during mental rotation is influenced by sex, menstrual cycle, and sex steroid hormones. Neuropsychologia, 45(14), 3203-3214. doi:10.1016/j.neuropsychologia.2007.06.011

Snow, M. E., Jacklin, C. N., \& Maccoby, E. E. (1983). Sex-of-Child Differences in FatherChild Interaction at One Year of Age. Child Development, 54(1), 227. doi: $10.2307 / 1129880$

Thomas, G. (2013). How to do your research project (2nd ed.). London: Sage.

Todd, B. K., Fischer, R. A., Di Costa, S., Roestorf, A., Harbour, K., Hardiman, P., \& Barry, J. A. (2018). Sex differences in children's toy preferences: A systematic review, meta- regression, and meta- analysis. Infant and Child Development, 27(2), n/a-n/a. doi:10.1002/icd.2064 
UNICEF. (1989). The United Nations Convention on the Rights of the Child. London: UNICEF

Warin, J., \& Adriany, V. (2017). Gender flexible pedagogy in early childhood education. Journal of Gender Studies, 26(4), 375-312. doi:10.1080/09589236.2015.1105738

Whyte, J. (1998). Childhood. In K. Trew \& J. Kremer (eds). Gender and Psychology. London: Arnold

Wingrave, M. (2016). Perceptions of gender in early years. Gender and Education, 1-20. doi:10.1080/09540253.2016.1258457

Wood, E., Desmarais, S., \& Gugula, S. (2002). The Impact of Parenting Experience on Gender Stereotyped Toy Play of Children. Sex Roles, 47(1), 39-49. doi:10.1023/A:1020679619728

Zero Tolerance. 2013. Just like a child: Respect gender equality in the early years A guide for childcare professionals. Zero Tolerance: Edinburgh 
Appendix 1: Sample of Parent Questionnaire

Questionnaire for Class Parents

Please tick which applies to you:

I am a.... $\quad$ Male $\square \quad$ Female $\square$ parent.

My child in $\square$ Class is a... Boy $\square \quad$ Girl $\square$.

1) How do you believe gender is formed?

Biologically

Socially

Both

Other

Please elaborate on your answer:

2) What 4 words would you use to describe a girl:

i).

ii)

iii)

iiii)

3) What 4 words would you use to describe a boy:

i).

ii)

iii)

iiii)

4) Do you feel that a child's gender is important to their development? Yes $\square \quad$ / No

Please elaborate on your answer: 
5) Does your child's gender influence how you interact and engage with them? Yes $\square$ / No $\square$

Please elaborate on your answer:

6) Do you feel that your son/daughter has any advantages due to their gender? Yes $\square$ / No

Please elaborate on your answer:

7) Do you feel that your son/daughter faces any disadvantages due to their gender? Yes $\square /$ No $\square$

Please elaborate on your answer: 


\section{Appendix 2: Sample of Practitioner Interview Questions}

\section{Interview questions for Practitioner focus group}

These questions are based on the interview topic questions for educators as outlined within the research of Chapman (2016) and edited for the purpose of this study.

- How do you think gender is formed within the early years?

- Do you feel that gender stereotypes are observed within early years? If so, how?

- Does gender affect your planning; and if so, how?

- What are your opinions about how a child's gender affects their behaviour (play, interactions, engagement etc)?

- What are your opinions about how a child's gender affects their opportunities? Be that educationally, socially or in adult life?

- What are your perceptions of stereotypical boy and girl behaviour?

○ Do you feel that educators conform to these stereotypical, gender-based perceptions within their practice?

○ What are your opinions on educators behaving either consciously or unconsciously on gender stereotypes?

- What else do you feel impacts the perceptions of gender roles and stereotypes surrounding the early years?

- Can you name 4 words you would use to describe a boy and 4 words to describe a girl? 